\title{
Factors associated with the intention to continue using tobacco among adolescents: A secondary analysis of the 2015 Global Youth Tobacco Survey in the Philippines
}

\author{
Reiner Lorenzo J. Tamayo ${ }^{1}$
}

AFFILIATION

1 College of Public Health, University of the Philippines, Manila, Philippines

CORRESPONDENCE TO

Reiner Lorenzo J. Tamayo. College of Public Health, University of the Philippines, 625 Pedro Gil Street, Ermita, Manila, Philippines. E-mail: renztamayo@gmail.com
ORCID ID: https://orcid.org/0000-0002-5130-4341

\section{KEYWORDS}

tobacco, smoking, adolescents, policies, Global Youth Tobacco Survey

Received: 10 October 2021, Revised: 27 October 2021

Accepted: 2 November 2021

\begin{abstract}
INTRODUCTION Smoking produces significant health problems affecting millions of people globally. It is the largest single cause of preventable deaths. This study aims to describe the characteristics of Filipino adolescent smokers aged 13-15 years and determine the factors associated with the intention to continue to use tobacco in the next 12 months among current smokers.

METHODS This was a secondary analysis of the 2015 Global Youth Tobacco Survey (GYTS) in the Philippines to determine the association of the following factors with the intention to continue to use tobacco in the next 12 months among current smokers: 1) exposure to anti-tobacco media messages, 2) exposure to health warnings on cigarette packages, and 3) being taught about the dangers of tobacco in any class.

RESULTS The adjusted odds of continuing to use of any form of tobacco in the next 12 months was higher $(\mathrm{AOR}=1.24$;
\end{abstract}

95\% CI: 0.62-2.49) among those who have not seen health warnings on cigarette packages and higher $(\mathrm{AOR}=1.32$; 95\% CI: 0.71-2.45) when not taught about tobacco in any of their classes. Finally, those who have not seen or heard antitobacco messages on television, radio, internet, billboards, posters, newspapers, magazines, or movies, were more likely (AOR=2.19; 95\% CI: $1.14-4.21$ ) to report their intention to continue to use tobacco.

CONCLUSIONS Understanding the relationship of different tobacco control strategies to adolescents' intention to continue using tobacco can contribute to the improvement of tobacco policies and programs and achieve effective tobacco control among the youth. A targeted anti-tobacco campaign in both traditional and new media should be considered an essential part of a comprehensive tobacco control program. Health warnings on cigarette packs should be supported by a policy banning the sale of single stick cigarettes.

\section{INTRODUCTION}

Tobacco use is one of the biggest public health threats globally and the most significant single cause of preventable deaths. Globally, it kills more than seven million a year, with more than six million of those deaths attributable to direct tobacco use. Around $80 \%$ of smokers worldwide live in low- and middle-income countries such as the Philippines ${ }^{1}$. Smoking, especially during adolescence, produces significant health problems, including respiratory illnesses, cancer, and cardiovascular disease ${ }^{2}$.

To address the growing tobacco epidemic, the Philippines started implementing tobacco control measures as early as 1987. Several tobacco control policies were enacted to:
1) increase tobacco taxes, 2) ban tobacco advertising or promotion, 3) designate smoke-free places, and 4) ban the sale of tobacco products to minors ${ }^{3}$.

Despite these actions, $47.5 \%$ of Filipino students aged 13-15 years were not prevented from buying cigarettes despite their age, while only $67.1 \%$ were taught in school about the dangers of tobacco use $\mathrm{e}^{4}$. Moreover, there were significant decreases in the prevalence of Filipino youth who saw anti-tobacco messages in the media (from 89.4\% in 2011 to $71.6 \%$ in 2015 ) and at sports or community events (from $88.8 \%$ in 2011 to $53.2 \%$ in 2015$)^{4}$.

In 2015, 14.5\% of Filipino students were current tobacco smokers (smoked tobacco anytime during the past 30 
days), while $12 \%$ were current cigarette smokers (smoked cigarettes anytime during the past 30 days) ${ }^{4}$. Current cigarette smoking among Filipino youth showed a declining trend from the year $2000^{4}$. However, a $34.8 \%$ increase in current cigarette smoking was observed between 2011 and $2015^{4}$. The latest Global Youth Tobacco Survey (GYTS) shows that one in ten students are current smokers and $0.7 \%$ have smoked cigarettes on 20 or more days in the past 30 days ${ }^{4}$.

It is crucial to look at adolescents' intention to continue to use tobacco, which can predict behavior. According to the Theory of Planned Behavior, a behavior is a result of the intention to do the behavior and the perceived control over it. Behavioral intentions are often influenced by the attitude towards the behavior, the subjective evaluation of the results of the behavior, and the perceived control over the behavior. While the relationship between intention and behavior is not always perfect, the intention is often used as a proxy for actual behavior.

Given inadequate information, young people often underestimate the risk of becoming addicted to smoking due to nicotine, which relates to underestimating future costs and consequences ${ }^{5}$. This myopic view on the ills of tobacco use and the external costs imposed on others, which result in premature death and illness, justifies government intervention through strategies including regulation, taxation, and information dissemination.

Hence, to reduce the prevalence of current tobacco use among the youth by $2 \%$ per year, the Philippines has to devise or reinvent its tobacco control and prevention strategies for the youth ${ }^{4}$. This study aims to look at three of the most common methods of message delivery and their relationship to adolescent smokers' intention to continue using tobacco.

Specifically, this study aimed to describe the characteristics of Filipino adolescent smokers aged 13-15 years and determine the association of the following factors with the intention to continue to use tobacco in the next 12 months among current smokers: 1 ) exposure to anti-tobacco media messages, 2) exposure to health warnings on cigarette packages, and 3) being taught about the dangers of tobacco in any class.

\section{METHODS}

\section{Data source}

This study was a secondary dataset analysis of the 2015 Global Youth Tobacco Survey in the Philippines, which was administered from January to March $2015^{4}$. The GYTS was developed by the Tobacco Free Initiative (TFI), United States Centers for Disease Control and Prevention (US CDC), and World Health Organization (WHO) in collaboration with representatives from the six WHO regions ${ }^{6}$. The GYTS is a school-based survey designed to monitor tobacco use among the youth and guide tobacco control program implementation and evaluation ${ }^{6}$.

The GYTS is a school-based survey that utilized a two- stage cluster sample design that produced representative samples of students in year levels that were associated with ages 13-15 years ${ }^{4,6}$. It uses a self-administered questionnaire to evaluate trends in tobacco use among adolescents and to guide the implementation and evaluation of tobacco prevention and control programs for the Filipino youth ${ }^{6}$.

The Philippines has conducted five rounds of the GYTS since 2000. The Philippine version of the GYTS is a nationally representative survey of students aged 13-15 years and is regularly used to generate data that are comparable to other countries $^{4}$. It utilizes a global standard to systematically monitor tobacco control indicators that include: data on the prevalence of cigarette and other tobacco use, exposure to secondhand smoke, accessibility and availability of tobacco products, the influence of media and advertising on the use of cigarettes, susceptibility, smoking cessation, and knowledge and attitudes towards tobacco use and policies ${ }^{4}$.

\section{Definition of variables}

\section{Current cigarette smoking}

Two questions were used to define current cigarette smoking: 1) 'Have you ever tried or experimented with cigarette smoking, even one or two puffs?' with response 'yes' or 'no'; and 2) 'During the past 30 days (one month), on how many days did you smoke cigarettes?' where answers were dichotomized (' 1 ' for those reporting 0 days in the past 30 days, and ' 2 ' for those reporting $\geq 1$ day in the past 30 days). Participants who have answered 'yes' in the first question and reported at least 1 day of cigarette use in the past 30 days were considered current cigarette smokers.

\section{Intention to continue using tobacco in the next 12 months}

Participants were asked to indicate their future intention to continue using any form of tobacco with four response options: 'definitely not', 'probably not', 'probably yes', and 'definitely yes'. For this study, the answers were dichotomized into 'yes' (combined 'probably yes' and 'definitely yes') and 'no' (combined 'probably not' and 'definitely not').

\section{Exposure to anti-tobacco media messages}

Participants were asked to indicate whether they have or have not seen or heard any anti-tobacco media messages on television, radio, internet, billboards, posters, newspapers, magazines, or movies during the past 30 days.

\section{Exposure to health warnings on cigarette packages}

Participants were asked whether they have or have not seen any health warnings on cigarette packages during the past 30 days using the following options: 'Yes but I didn't think much of them', and 'Yes, and they led me to think about quitting smoking or not starting'. The answers were dichotomized into 'yes' and 'no'.

\section{Taught the dangers of tobacco use}

Participants were asked whether they have or have not 
been taught about the dangers of tobacco use in any of their classes in the past 12 months with the options: 'yes', 'no', and 'do not know'. Only participants who answered 'yes' or 'no' were included in the analysis.

\section{Statistical analysis}

Descriptive statistics were used to identify the demographic characteristics of the participants. Crude and adjusted logistic regression analyses were performed to examine the association between independent variables and intention to continue using tobacco products among current smokers. In the logistic regression analyses, odds ratios and confidence intervals were calculated. The logistic regression models were adjusted for the effects of covariates such as age, sex, and type of school.

All analyses were conducted using JASP version 0.14.1, which was released on 17 December 2020. JASP is a free and open-source program for statistical analysis. The statistical software offers standard analysis procedures in classical and Bayesian form.

\section{RESULTS}

There were 8789 students who participated in the 2015 GYTS survey. Of these, only 5885 were aged 13-15 years. Their number was further reduced by identifying participants who reported having tried smoking even one or two puffs and have smoked at least once in the past 30 days. Finally, a total of 287 students aged 13-15 years were included in the analysis. Of which, $73.87 \%$ (212) said they do not intend to smoke in the next 12 months. Most of the respondents were male and from public schools. The characteristics of the respondents are given in Table 1.

The majority (89\%) of the respondents bought cigarettes by the stick and saw health warnings on cigarette packages (81\%). About $79 \%$ saw anti-tobacco media messages while $75 \%$ were taught about the dangers of tobacco in their classes.

Crude and adjusted regression analyses were performed to determine the crude and adjusted odds ratios for each factor. The odds ratios were adjusted for age, sex, and type of school. The results are presented in Table 2.

The crude analysis showed that the odds of using any form of tobacco in the next 12 months are 19\% (OR=1.19; 95\% CI: 0.60-2.37) higher if a student has not seen health warnings on cigarette packages and $27 \%(\mathrm{OR}=1.27$; $95 \% \mathrm{CI}$ : 0.69-2.33) higher if not taught about the dangers of tobacco in class. Meanwhile, those who have not seen anti-tobacco media messages were 2.31 (OR=2.31; 95\% CI: $1.22-4.35$ ) times more likely to continue using tobacco in the next 12 months.

After adjusting all factors for confounders, the odds of adolescents continuing to use of any form of tobacco in the next 12 months were $24 \%$ (AOR=1.24; 95\% CI: 0.62-2.49) higher among those who have not seen health warnings on cigarette packages and 32\% (AOR=1.32; 95\% CI: 0.71-2.45) higher when not taught about tobacco in any of their classes.
Finally, in the adjusted analysis, those who have not seen or heard anti-tobacco messages on television, radio, internet, billboards, posters, newspapers, magazines, or movies were 2.19 times (AOR=2.19; 95\% CI: 1.14-4.21) more likely to use tobacco in the next 12 months compared to those who have seen anti-tobacco media messages.

Table 1. Characteristics of Filipino adolescents aged 13-15 years who are current smokers, 2015 ( $\mathrm{N}=287)^{*}$

\begin{tabular}{|c|c|c|c|}
\hline \multirow[t]{2}{*}{ Characteristics } & \multirow[t]{2}{*}{ n (\%) } & \multicolumn{2}{|c|}{$\begin{array}{c}\text { Intention to continue } \\
\text { smoking }{ }^{\mathrm{a}} \\
\text { n (\%) }\end{array}$} \\
\hline & & No & Yes \\
\hline \multicolumn{4}{|l|}{ Age (years) } \\
\hline 13 & $60(20.91)$ & 49 (81.67) & $10(16.67)$ \\
\hline 14 & $100(34.84)$ & $78(78.00)$ & $22(22.00)$ \\
\hline 15 & $127(44.25)$ & 85 (66.93) & $39(30.71)$ \\
\hline \multicolumn{4}{|l|}{ Sex } \\
\hline Male & $220(76.65)$ & 159 (72.27) & $58(26.36)$ \\
\hline Female & 67 (23.34) & 53 (79.10) & $13(19.40)$ \\
\hline \multicolumn{4}{|l|}{ Type of school } \\
\hline Public & 240 (83.62) & $179(74.58)$ & $58(24.17)$ \\
\hline Private & 47 (16.38) & 33 (70.21) & $13(27.66)$ \\
\hline
\end{tabular}

\begin{tabular}{lrrr|}
$\begin{array}{l}\text { Method } \\
\text { of buying } \\
\text { cigarettes }\end{array}$ & & & \\
\hline Pack & $31(10.80)$ & $22(70.97)$ & $7(22.58)$ \\
\hline Sticks & $256(89.20)$ & $190(74.22)$ & $64(25.00)$ \\
\hline $\begin{array}{l}\text { Saw health } \\
\text { warnings } \\
\text { on cigarette } \\
\text { packages }\end{array}$ & & & \\
\hline Yes & $234(81.53)$ & $175(74.79)$ & $57(24.36)$ \\
\hline No & $52(18.12)$ & $36(69.23)$ & $14(26.92)$ \\
\hline
\end{tabular}

\section{Saw anti- \\ tobacco media messages}

\begin{tabular}{|lrrr|}
\hline Yes & $226(78.75)$ & $174(76.99)$ & $48(21.24)$ \\
\hline No & $54(18.82)$ & $33(61.11)$ & $21(38.89)$ \\
\hline $\begin{array}{l}\text { Taught dangers } \\
\text { of tobacco }\end{array}$ & & & \\
\hline Yes & $216(75.26)$ & $162(75.00)$ & $51(23.61)$ \\
No & $71(24.74)$ & $50(70.42)$ & $20(28.17)$
\end{tabular}

* Missing values not included in the table, but included in the percentage computation. aParticipants were asked to indicate their future intention to continue using any form of tobacco in the next 12 months. 
Table 2. Logistic regression of factors affecting intention to continue smoking among Filipino adolescents aged 13-15 years who are current smokers, $2015(\mathrm{~N}=287)$

\begin{tabular}{|c|c|c|c|c|}
\hline Factors & \multicolumn{2}{|c|}{ OR $(95 \%$ CI $)$} & \multicolumn{2}{|c|}{ AOR* $(95 \%$ CI $)$} \\
\hline \multicolumn{5}{|c|}{$\begin{array}{l}\text { Exposure to anti- } \\
\text { tobacco media } \\
\text { messages }^{\text {a }}\end{array}$} \\
\hline Yes (Ref.) & 1 & & 1 & \\
\hline No & 2.31 & $(1.22-4.35)$ & 2.19 & $(1.14-4.21)$ \\
\hline \multicolumn{5}{|c|}{$\begin{array}{l}\text { Exposure to } \\
\text { health warnings } \\
\text { on cigarette } \\
\text { packages }^{\text {b }}\end{array}$} \\
\hline Yes (Ref.) & 1 & & 1 & \\
\hline No & 1.19 & $(0.60-2.37)$ & 1.24 & $(0.62-2.49)$ \\
\hline \multicolumn{5}{|c|}{$\begin{array}{l}\text { Taught dangers } \\
\text { of tobacco in } \\
\text { class }^{c}\end{array}$} \\
\hline Yes (Ref.) & 1 & & 1 & \\
\hline No & 1.27 & $(0.69-2.33)$ & 1.32 & $(0.71-2.45)$ \\
\hline \multicolumn{5}{|c|}{$\begin{array}{l}\text { *AOR: adjusted odds ratio; adjusted for age, sex, and type of school. a Participants' } \\
\text { exposure to anti-tobacco media messages on television, radio, internet, billboards, } \\
\text { posters, newspapers, magazines, or movies during the past } 30 \text { days. b Participants' } \\
\text { exposure to any health warnings on cigarette packages during the past } 30 \text { days. c } \\
\text { Participants' exposure to the dangers of tobacco use in any of their classes in the } \\
\text { past } 12 \text { months. }\end{array}$} \\
\hline
\end{tabular}

\section{DISCUSSION}

Non-exposure to anti-tobacco media messages and health warnings on cigarette packages increases the odds of continuing tobacco use among adolescents aged 13-15 years.

The results of this study support the enforcement of the WHO Framework Convention on Tobacco Control's (FCTC) non-price measures to reduce the demand for tobacco among the youth ${ }^{7}$. In particular, programs and policies on public awareness and education, advertising, packaging, and labeling may be effective in curbing tobacco use among current cigarette smokers aged 13-15 years. This study provides further emphasis on the value of raising public awareness and health consciousness through a combination of various communication strategies which can form part of an effective tobacco control program.

Smokers are often not fully informed about the health risks posed by tobacco use. There are still gaps in their understanding of the impact of tobacco on their health. Moreover, people generally tend to behave according to the perceived benefits and consequences of their actions. In the case of smokers, incomplete or inadequate information about the risks of tobacco smoking often leads poorly-informed smokers to underestimate the risks of their actions, and therefore behave in a manner that is opposite to the situation when complete information is provided to them. Since people react to perceived risks by reducing risky behavior, a situation where there is incomplete information, therefore, means a world with higher smoking prevalence.

Jha et al. ${ }^{8}$ describe two reasons why smokers tend to be ill-informed. First, the tobacco industry does not provide this information, and sometimes, even hides or distorts it. The tobacco industry does not have any incentive to provide health information that has the potential to reduce tobacco product consumption ${ }^{8}$. It does not only hide information on the health effects of tobacco use, it also makes use of various means to advertise and promote its products as 'safe' and/or 'healthy', especially among the youth ${ }^{8}$. Second, there is usually a long period between starting to smoke and the onset of illness. Such delay obscures the link between smoking and diseases, unlike other risky behaviors where costs and benefits are usually immediately appreciated. It is also due to this time gap that the youth often cannot imagine and think of the future consequences of their behavior, which makes it difficult to instill health consciousness among them ${ }^{8}$. By the time they understand the health risks associated with smoking and are ready to quit smoking, addiction has taken hold.

Given inadequate information, young people often underestimate the risk of becoming addicted to smoking due to nicotine, which relates to the underestimation of future costs and consequences from smoking. The notion that the youth will make unwise, uninformed decisions is recognized by the government and it is further affected by addiction and inadequate information. Nicotine addiction weakens the argument that smokers should exercise sovereignty. As such, hard-hitting campaigns and strategies are warranted to compel tobacco users to quit, increase awareness, and promote behavior change among smokers and non-smokers.

The majority of the respondents (81\%) in this study saw health warnings on cigarette packages. Among them, about $75 \%$ expressed no intention of continuing to use any tobacco product (i.e. quit smoking) in the next 12 months. At the time of the survey, however, only text warnings on the lower $30 \%$ of the cigarette pack's panel were required by law ${ }^{3}$. The law also does not prohibit the sale of single cigarette sticks making it easier for the youth to obtain tobacco products and greatly reduces exposure to health warnings ${ }^{3,7}$.

The Philippines was once called a country having a 'sachet economy' as it allows a consumer to make smaller cash outlays for smaller packages ${ }^{9}$. Smokers resort to buying one or two sticks at a time with an accompanying free lightup service from the vendor, instead of buying a pack of cigarettes. Buying cigarettes per stick, as opposed to buying a pack, significantly removes the probability of a smoker or potential smoker to see these health warnings and thus defeats the purpose of health warnings on cigarette packs. Unsurprisingly, many of the study participants (89\%) bought single cigarette sticks, and $25 \%$ did not report an intention to quit smoking in the next 12 months.

With the end goal of effectively instilling health 
consciousness and deterring potential smokers, the graphic health warnings (GHWs) on tobacco product packages were introduced to deliberately present the harmful effects of tobacco use and to change the wrongful notions associated with smoking ${ }^{10}$. Graphic health warnings are intended to prompt smokers to think that they could contract diseases depicted in the pictures. Worldwide, GHWs were proven effective in prompting smokers to think about the dangers of smoking which are associated with increased intention to quit $^{11-13}$. Moreover, this study showed that non-exposure to health warnings leads to higher odds of intention to continue smoking among adolescents. But despite this evidence, graphic health warnings will fall short in attaining the maximum benefit they promise, due to lapses in the policy's implementation. Hence, banning the sale of single cigarette sticks should be explored to amplify the effects of health warnings on cigarette packages.

This study also found that the proportion of students who intend to continue smoking was lower for those who received information about the dangers of tobacco in their classes (23.61\%) compared with those who did not receive such information (28.17\%). In Indonesia, school-based education programs have been shown to effectively increase knowledge on the negative effects of smoking ${ }^{14}$. In the Philippines, however, it was only in 2016 when the Department of Education mandated schools to inform students about the hazards of tobacco use and exposure to secondhand smoke $^{15}$. This warrants the strengthening of the Department of Education's learning modules on tobacco prevention and control, and the reinforcement of such teachings through health education campaigns correcting common myths and misconceptions.

Current evidence suggests that anti-tobacco media messages are effective in: 1) reducing the urge to smoke among current smokers, 2) building awareness about the harmful effects of tobacco use and secondhand smoke, and 3) changing attitudes and beliefs about smoking and quitting ${ }^{16-19}$. This study found that among those who saw anti-tobacco media messages, about $79 \%$ had no intention of continuously using tobacco in the next 12 months. More importantly, non-exposure to anti-tobacco media messages increased the odds of continuously using any tobacco products in the future. These findings suggest the necessity of promoting anti-tobacco messages on television, radio, internet, billboards, posters, newspapers, magazines, or movies. Hence, more investment in promoting antitobacco media messages through these platforms should be considered.

Messages that induce fear, disgust, and loss, were found to be more effective in reducing the intention to smoke among current smokers and prompting them to quit when compared with messages that elicit positive emotions ${ }^{19}$. These anti-tobacco messages are most effectively delivered when they are culturally targeted or disseminated through the internet ${ }^{16,17}$.
Anti-tobacco campaigns should deliver strong messages to quit using various communication channels. As the Philippines ranks among the highest in terms of hours spent on social media ${ }^{20}$, an online health promotion campaign incorporating anti-tobacco media messages targeting the youth may be considered as a component of the tobacco control program. Evidence also shows that television advertisements showing graphic messages are effective across all income groups ${ }^{18,21}$. Hence, mass media campaigns on television and/or radio may play a vital role in promoting smoking cessation.

\section{Limitations}

This study provides preliminary evidence on the effect of various strategies to reduce the overall prevalence of smoking among adolescents aged 13-15 years. The cross-sectional design of the study does not permit causal relationships to be assumed. Conclusions made in the study are not generalizable to the general population, but may provide useful insights to certain settings with similar contexts. A larger sample size is needed to provide more accurate estimates.

\section{CONCLUSIONS}

To effectively reduce the overall prevalence of smoking among adolescents aged 13-15 years, we must consider the implementation of evidence-based strategies to inform the youth about the harmful effects of tobacco use. Results from this study suggest that non-exposure to anti-tobacco media messages increases the odds of adolescents continuing to use tobacco in the future. Thus, a targeted anti-tobacco campaign in both traditional and new media should be considered an essential part of a comprehensive tobacco control program. Health warnings on cigarette packs should be supported by a policy banning the sale of single sticks of cigarettes.

\section{REFERENCES}

1. World Health Organization. Tobacco fact sheet. World Health Organization; 2020. Accessed May 25, 2021. https://www. who.int/news-room/fact-sheets/detail/tobacco

2. Preventing Tobacco Use Among Young People, A Report of the Surgeon General: Executive Summary. MMWR Recomm Rep. 1994;43(RR-4):i-11. Accessed May 25, 2021. https:// www.cdc.gov/mmwr/PDF/rr/rr4304.pdf

3. Republic Act No. 9211: AN ACT REgulating THE PACKAGING, USE, SALE, DISTRIBUTION AND ADVERTISEMENTS OF TOBACCO PRODUCTS AND FOR OTHER PURPOSES, 12th Congress (2003). S. No. 1859, H. No. 5950. June 23, 2003. Accessed May 25, 2021. https://mirror. officialgazette.gov.ph/2003/06/23/republic-act-no-9211/

4. 2015 Global Youth Tobacco Survey: Country Report, Philippines. Republic of the Philippines Department of Health, Epidemiology Bureau, U.S. Department of Health \& Human Services, Centers for Disease Control and Prevention; 2017. Accessed October 27, 2021. https://doh.gov.ph/sites/ 
default/files/publications/FinalGYTS_CountryReport.pdf

5. Amrock SM, Weitzman M. Adolescents' Perceptions of Light and Intermittent Smoking in the United States. Pediatrics. 2015;135(2):246-254. doi:10.1542/peds.2014-2502

6. Global youth tobacco survey. World Health Organization. Accessed May 2, 2021. http://www.who.int/tobacco/ surveillance/gyts/en/

7. World Health Organization. WHO Framework Convention on Tobacco Control. World Health Organization; 2005. Accessed May 25, 2021. http://apps.who.int/iris/bitstream/ handle $/ 10665 / 42811 / 9241591013$.pdf;jsessionid $=7$ 8E32634EC0B219D8E1BA3F8F9EEE51A? sequence $=1$

8. Jha P, Chaloupka FJ, eds. Tobacco control in developing countries. Oxford University Press; 2000. Accessed May 25, 2021. https://documents1.worldbank.org/curated/ en/602821468330954036/pdf/709670WP0tobac00 Box370064B00PUBLIC0.pdf

9. World Bank Group. Market Study for Philippines: Plastics Circularity Opportunities and Barriers. World Bank; 2021. Marine Plastics Series: East Asia and Pacific Region. Accessed October 27, 2021. https://openknowledge.worldbank.org/ handle/10986/35295

10. Republic Act No. 10643: An act to effectively instill health consciousness through graphic health warnings on tobacco products, 16th Congress (2013). S. No. 27, H. No. 4590. July 15, 2014. Accessed May 25, 2021. https://www. officialgazette.gov.ph/2014/07/15/republic-act-no-10643/

11. Shadel WG, Martino SC, Setodji CM, Dunbar M, Scharf D, Creswell KG. Do graphic health warning labels on cigarette packages deter purchases at point-of-sale? An experiment with adult smokers. Health Educ Res. 2019;34(3):321-331. doi:10.1093/her/cyz011

12. Rahman SM, Alam MS, Zubair A, et al. Graphic health warnings on tobacco packets and containers: compliance status in Bangladesh. Tob Control. 2019;28(3):261-267. doi:10.1136/tobaccocontrol-2018-054249

13. Ratih SP, Susanna D. Perceived effectiveness of pictorial health warnings on changes in smoking behaviour in Asia: a literature review. BMC Public Health. 2018;18(1):1165. doi:10.1186/s12889-018-6072-7

14. Tahlil T, Woodman RJ, Coveney J, Ward PR. The impact of education programs on smoking prevention: a randomized controlled trial among 11 to 14 year olds

\section{ACKNOWLEDGEMENTS}

This study used data from the Global Youth Tobacco Survey (GYTS), which is supported by the World Health Organization and the US Centers for Disease Control and Prevention. I would like to express my gratitude to Kim Co and Dan Louie Renz Tating for their guidance in data analysis and interpretation, and for providing feedback on the manuscript.

\section{CONFLICTS OF INTEREST}

The author has completed and submitted the ICMJE Form for Disclosure of Potential Conflicts of Interest and none was reported.

FUNDING

There was no source of funding for this research. in Aceh, Indonesia. BMC Public Health. 2013;13(1):367. doi:10.1186/1471-2458-13-367

15. Policy and Guidelines on Comprehensive Tobacco Control. DepEd Order No. 48, s. 2016. Republic of the Philippines, Department of Education; 2016. Accessed October 27, 2021. https://www.deped.gov.ph/wp-content/uploads/2016/06/ DO_s2016_048.pdf

16. Gould GS, McEwen A, Watters T, Clough AR, van der Zwan R. Should anti-tobacco media messages be culturally targeted for Indigenous populations? A systematic review and narrative synthesis. Tob Control. 2013;22(4):e7. doi:10.1136/tobaccocontrol-2012-050436

17. Elser H, Hartman-Filson M, Alizaga NM, Vijayaraghavan M. Exposure to pro- and anti-tobacco messages online and offline among people experiencing homelessness. Prev Med Rep. 2019;15:100944. doi:10.1016/j.pmedr.2019.100944

18. National Institute for Health and Care Excellence. Stop smoking interventions and services. March 28, 2018. Accessed May 26, 2021. https://www.nice.org.uk/guidance/ ng92/resources/stop-smoking-interventions-and-servicespdf-1837751801029

19. Reis ES, e Arriaga PPL, Postolache OA. Fear or Humour in anti-smoking campaigns? Impact on perceived effectiveness and support for tobacco control Policies. Medo ou Humor em campanhas antitabágicas? 0 impacto na perceção de eficácia e apoio a políticas antitabágicas. Cien Saude Colet. 2019;24(12):4727-4738. doi:10.1590/1413-812320182412.09322018

20. Filipinos lead the world in time spent on social media, internet. ABS-CBN NEWS. February 1, 2021. Accessed May 26, 2021. https://news.abs-cbn.com/business/02/01/21/ filipinos-lead-the-world-in-time-spent-on-social-mediainternet

21. World Health Organization. WHO Report on the Global Tobacco Epidemic 2013: Enforcing bans on tobacco advertising, promotion and sponsorship. World Health Organization; 2013. Accessed October 27, 2021. www.who. int/tobacco/global_report/2013/en/

ETHICAL APPROVAL AND INFORMED CONSENT

Ethical approval and informed consent were not required for this study, as publicly available data were used.

\section{DATA AVAILABILITY}

The data supporting this research are available from the WHO NCD Microdata Repository: https://extranet.who.int/ncdsmicrodata/index. php/catalog/756/datafile/F1.

PROVENANCE AND PEER REVIEW

Not commissioned; externally peer reviewed. 